\title{
A study of maternal and perinatal outcome in patients of postpartum hemorrhage in a tertiary care hospital, Gujarat
}

\author{
Ami H. Shah, Divyesh N. Panchal*
}

Department of Obstetrics and Gynecology, GCS Medical College, Ahmedabad, Gujarat, India

Received: 04 May 2021

Revised: 23 May 2021

Accepted: 24 May 2021

\section{*Correspondence:}

Dr. Divyesh N. Panchal,

E-mail: divyeshpanchal9@gmail.com

Copyright: (C) the author(s), publisher and licensee Medip Academy. This is an open-access article distributed under the terms of the Creative Commons Attribution Non-Commercial License, which permits unrestricted non-commercial use, distribution, and reproduction in any medium, provided the original work is properly cited.

\section{ABSTRACT}

Background: Postpartum hemorrhage (PPH) is significant factor for maternal mortality. Prevalence of PPH is $6.0 \%$ worldwide and highest prevalence was noted in Africa which is almost $10.1 \%$. In India, maternal hemorrhage is the very common factor for maternal mortality. The objective of the study was to understand incidence of PPH and various risk factors for it, to study maternal morbidity and mortality associated with PPH and to study the effective mode of management in PPH.

Methods: This prospective study was done among 50 cases of postpartum haemorrhage out of 13,628 deliveries at civil hospital, Asarwa, Ahmedabad during November 2008 to October 2010 and analysis was done regarding patients' socio demographic characteristics, various risk factors, causes and maternal and perinatal outcome.

Results: Incidence of PPH was $0.36 \%$. Almost $>85 \%$ cases were belonged to 20-34 years age group. Highest cases $(38 \%)$ seen in primigravida and $72 \%$ cases have normal vaginal delivery. Anemia noted in highest cases (22\%) and $68 \%$ cases have most common etiology was atonicity. Birth weight $<2.5 \mathrm{~kg}$ found in $36 \%$ cases. Most common maternal outcome was fever (16\%) and $72 \%$ cases delivered healthy and alive birth.

Conclusions: The patients were mostly primiparous. The commonest associated medical condition was anemia. The commonest underlying cause of PPH was atonicity of the uterus. Commonest maternal outcome was fever. Out of total births, $72.0 \%$ were alive and healthy babies followed by $18.0 \%$ babies were still birth.

Keywords: Atonicity, Maternal outcome, Perinatal outcome, PPH

\section{INTRODUCTION}

In both developing and developed countries, postpartum hemorrhage $(\mathrm{PPH})$ is significant factor for maternal mortality. It is defined as blood loss of more than $500 \mathrm{ml}$ in normal vaginal delivery and more than $1000 \mathrm{ml}$ in a case of caesarean section or amount of blood loss that can affect hemodynamic stability of patient. ${ }^{1,2} \mathrm{PPH}$ is important element of maternal morbidity and mortality, responsible for almost $33.0 \%$ of all pregnancy-related deaths in Africa and Asia. ${ }^{3}$

Prevalence of PPH is $6.0 \%$ worldwide and highest prevalence was noted in Africa which is almsot $10.1 \% .{ }^{4}$ In India, maternal hemorrhage is the very common factor for maternal mortality. Maternal mortality due to PPH can be preventable because incidence of maternal deaths due to postpartum hemorrhage is very low in developed countries. ${ }^{5}$ Risk factor for PPH was noted that the history of prior PPH, nulliparity, overdistended uterus, placental abnormalities, such as placenta praevia or placenta accrete, coagulation abnormalities, anaemia, induction of labour, augmentation of labour, or use of an epidural and prolonged labour. ${ }^{6-12}$

Active management of third stage of labor is being encouraged in India like developing countries for prevention of PPH like complication because atonicity of uterus is the commonest cause of postpartum hemorrhage. ${ }^{13}$ Duhan et al observed that out of total births, 
$75 \%$ were alive and healthy babies followed by $16 \%$ babies who were admitted in Neonatal Intensive Care Unit (NICU). Prevention steps like encouragement of regular antenatal visits, timely referral of high-risk patients, training of health personals and timely intervention can prevent many maternal and neonatal deaths. ${ }^{14}$ The objective of the study were to understand incidence of PPH and various risk factors for it, to study maternal morbidity and mortality associated with $\mathrm{PPH}$ and to study the effective mode of management in PPH.

\section{METHODS}

This prospective study was done among 50 cases of PPH out of 13,628 deliveries at civil hospital, Asarwa, Ahmedabad during November 2008 to October 2010. Data collection was done after ethical permission from institutional ethical committee and informed consent of clients. This study included all emergency and booked patients having pregnancy more than 28 weeks. Active management of third stage of labor was done in all patients delivered at our institute which involved uterotonic drug administration, early cord clamping and control cord traction. The patients who delivered outside and referred as a case of PPH were analyzed and managed actively. Blood loss was assessed on the basis of measurements from kidney tray and blood loss on linen, mops and sponges. Detailed history was taken, thorough clinical examination was done, examination findings were noted to find out possible causes of $\mathrm{PPH}$ and necessary investigation were carried out. Patients were resuscitated by IV fluids and blood transfusion; medical management was given and operative interventions were done when required. Morbidity and mortality were analysed among treated patients. The data were recorded in an excel sheet and descriptive analysis was performed with the use of Epi info statistical software, CDC and Atlanta.

\section{RESULTS}

Present study observed the incidence of PPH was $0.36 \%$ out of total 13,628 total deliveries.

Table 1 shows that $2 \%, 86 \% \& 12 \%$ cases belonged to age $0-19,20-34$ and $>34$ years respectively. Almost $86 \%$ cases were attended in emergency. Almost 38\%, 20\%, 24\%, $8 \%$ \&and $10 \%$ cases were primi, $2^{\text {nd }}, 3^{\text {rd }}, 4^{\text {th }}$ and $5^{\text {th }}$ or more parity respectively. Around $84 \%$ cases have spontaneous delivery and remaining have induced or augmented labor. Almost $72 \%, 4 \%, 2 \%$ and $22 \%$ cases were delivered baby by vaginal delivery, forceps, vacuum \& LSCS method respectively.

Associated medical condition like anaemia, jaundice, fever, cardiac and renal in 22\%, 4\%, 14\%, 2\% and $2 \%$ cases respectively. Almost $16 \%, 2 \%, 4 \%$ and $16 \%$ cases have pre 1 C.S, pre 2 C.S, pre 3 C.S and MTP/D and E obstetrical history respectively.
Around 68\%, 28\% and 4\% cases have etiology for PPH was atonic, traumatic and coagulation disorders respectively. Birth weight was $<2.5 \mathrm{~kg}, 2.5-3.5 \mathrm{~kg}$ and $>3.5 \mathrm{~kg} 36 \%$ noted in $36 \%, 60 \%$ and $4 \%$ cases respectively.

Table 1: Socio-clinical characteristics of study participants $(\mathbf{N}=\mathbf{5 0})$.

\begin{tabular}{|c|c|}
\hline Characteristics & Number (\%) \\
\hline \multicolumn{2}{|l|}{ Age (years) } \\
\hline $0-19$ & $1(2)$ \\
\hline $20-34$ & $43(86)$ \\
\hline$>34$ & $6(12)$ \\
\hline \multicolumn{2}{|l|}{ Registration } \\
\hline Booked & $7(14)$ \\
\hline Emergency & $43(86)$ \\
\hline \multicolumn{2}{|l|}{ Parity } \\
\hline Primi & $19(38)$ \\
\hline 2nd & $10(20)$ \\
\hline $3 \mathrm{rd}$ & $12(24)$ \\
\hline 4th & $4(8)$ \\
\hline 5 th or more & $5(10)$ \\
\hline \multicolumn{2}{|l|}{ Mode of delivery } \\
\hline Vaginal delivery & $36(72)$ \\
\hline Forceps & $2(4)$ \\
\hline Vacuum & $1(2)$ \\
\hline LSCS & $11(22)$ \\
\hline \multicolumn{2}{|c|}{ Associated medical conditions } \\
\hline Anaemia & $11(22)$ \\
\hline Jaundice & $2(4)$ \\
\hline Fever & $7(14)$ \\
\hline Cardiac & $1(2)$ \\
\hline Renal & $1(2)$ \\
\hline \multicolumn{2}{|l|}{ Post obstetrical history } \\
\hline Pre 1 C.S. & $8(16)$ \\
\hline Pre 2 C.S. & $1(2)$ \\
\hline Pre 3 C.S. & $2(4)$ \\
\hline MTP/D and E & $8(16)$ \\
\hline \multicolumn{2}{|l|}{ Etiology } \\
\hline Atonic & $34(68)$ \\
\hline Traumatic & $14(28)$ \\
\hline Coagulation disorders & $2(4)$ \\
\hline \multicolumn{2}{|l|}{ Birth weight (kg) } \\
\hline$<2.5$ & $18(36)$ \\
\hline $2.5-3.5$ & $30(60)$ \\
\hline$>3.5$ & $2(4)$ \\
\hline
\end{tabular}

Table 2 shows that maternal outcome like fever, pulmonary edema, lactation failure, renal failure, hypovolaemic shock, hemolytic jaundice, DIC and wound gap noted in $16 \%, 2 \%, 2 \%, 2 \%, 2 \%, 4 \%, 14 \%$ and $6 \%$ cases respectively.

Table 3 shows that perinatal outcome like healthy, still birth noted in $72 \%, 18 \%$, and $10 \%$ cases respectively. 
Table 2: Maternal outcome $(\mathbf{N}=50)$.

\begin{tabular}{|ll|}
\hline Outcome & Number $(\%)$ \\
\hline Fever & $8(16)$ \\
\hline Pulmonary edema & $1(2)$ \\
\hline Lactation failure & $1(2)$ \\
\hline Renal failure & $1(2)$ \\
\hline Hypovolaemic shock & $1(2)$ \\
\hline Hemolytic jaundice & $2(4)$ \\
\hline DIC & $7(14)$ \\
\hline Wound gap & $3(6)$ \\
\hline
\end{tabular}

Table 3: Perinatal outcome $(\mathrm{N}=50)$.

\begin{tabular}{|ll|}
\hline Outcome & Number $(\%)$ \\
\hline Healthy & $36(72)$ \\
\hline Still birth & $9(18)$ \\
\hline Death & $5(10)$ \\
\hline
\end{tabular}

Table 4 shows that treatment like medical treatment, vaginal packing, uterine packing, manual removal of placenta, uterine artery ligation, ovarian artery ligation, internal iliac artery ligation, subtotal hysterectomy, total hysterectomy and reposition of inverted uterine given in $96 \%, 28 \%, 26 \%, 4 \%, 6 \%, 2 \%, 4 \%, 2 \%, 8 \%$ and $2 \%$ cases respectively.

Table 4: Treatment of established PPH $(\mathrm{N}=50)$.

\begin{tabular}{|ll|}
\hline Treatment & No. of patients (\%) \\
\hline Medical treatment & $48(96)$ \\
\hline Vaginal packing & $14(28)$ \\
\hline Uterine packing & $13(26)$ \\
\hline Manual removal of placenta & $2(4)$ \\
\hline Uterine artery ligation & $3(6)$ \\
\hline Ovarian artery ligation & $1(2)$ \\
\hline Internal iliac artery ligation & $2(4)$ \\
\hline Subtotal hysterectomy & $1(2)$ \\
\hline Total hysterectomy & $4(8)$ \\
\hline Reposition of inverted uterine & $1(2)$ \\
\hline Suturing of tear & \\
\hline Cervical & $9(18)$ \\
\hline Vaginal & $4(8)$ \\
\hline Perineal & $2(4)$ \\
\hline Episiotomy resuturing & $2(4)$ \\
\hline
\end{tabular}

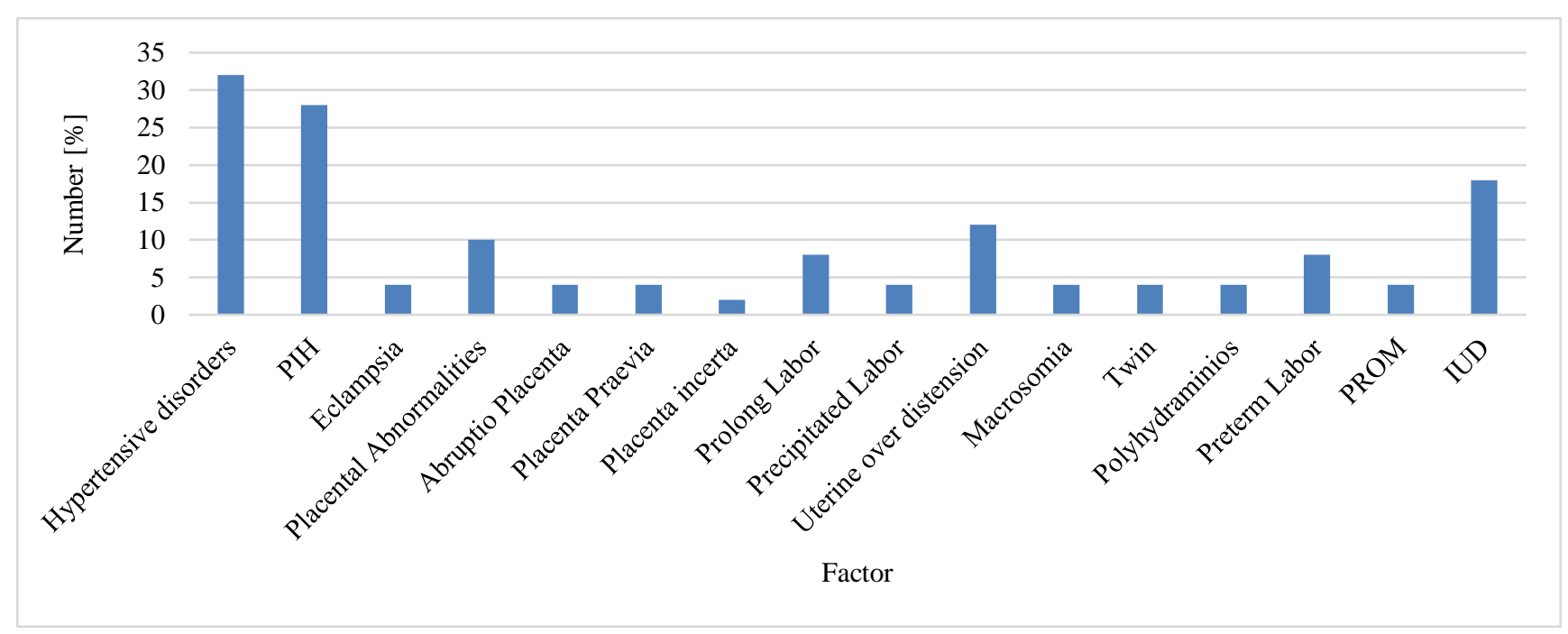

Figure 1: Associated risk factors during pregnancy and labor $(\mathrm{N}=50)$.

Figure 1 shows that associated risk factor like hypertensive disorders, PIH, eclampsia, placental abnormalities, abruptio placenta, placenta praevia, placenta incerta, prolong labor, precipitated labor, uterine over distension, macrosomia, twin, polyhydraminios, preterm labor, PROM and IUD observed in $32 \%, 28 \%, 4 \%, 10 \%, 4 \%$, $4 \%, 2 \%, 8 \%, 4 \%, 12 \%, 4 \%, 4 \%, 4 \%, 8 \%, 4 \%$ and $18 \%$ cases respectively.

\section{DISCUSSION}

Present study observed the incidence of PPH was $0.36 \%$. As stated above the maternal hemorrhage is a leading cause of maternal morbidity and mortality. Present study found that almost $>85 \%$ cases were belonged to $20-34$ years age group. Present study noted that highest cases seen in primigravida. This finding is correlate with the study done by Duhan et al, Kramer et al, Sheldon et al, Combs et al, Tsu et al and Gilbert et al. ${ }^{6-9,14-16}$ Contrary observation that a parity of three or more was also significantly associated with increased odds of PPH was noted in study done by Cotter et al and Jaleel et al. ${ }^{17,18}$

Present study noted that $72 \%$ cases have normal vaginal delivery. Holm et al said that compared with intended vaginal delivery, planned caesarean delivery was associated with a reduced risk of severe postpartum hemorrhage. ${ }^{19}$ Wei et al said that vaginal deliveries tended 
to lead to greater postpartum blood loss than cesarean sections, and that blood loss based on change of hemoglobin levels deviated substantially from loss estimated by midwives or doctors during delivery, especially vaginal deliveries. ${ }^{20}$ In vaginal delivery, especially in patients with blood loss more than $1000 \mathrm{ml}$, the amount of bleeding can be significantly underestimated.

Present study observed that anemia was the most common associate medical condition among study participants. This finding is correlate with the study done by Duhan et al. ${ }^{14}$ Anemia is also one of the most significant factors which complicates maternal outcome in patients with postpartum hemorrhage. Therefore, it is very important to identify high risk patients during antenatal visits and modification of those risk factors if possible. Anemia is shown to be the most common cause of morbidity in few other studies. $^{21,22}$

Present study found that atonicity was the most common etiology among the cases. This is in correlation with various studies, where atonicity was the most common cause of PPH, followed by traumatic PPH as the second most common cause of PPH. ${ }^{23}$

Present study noted that almost $36 \%$ cases have delivered low birth baby. Kramer et al observed LBW incidence was $6.3 \%$ and Rathi et al observed in $32.0 \%$ cases. ${ }^{15,24}$ Present study noted that most common maternal outcome was fever and wound gap. Few incidences of pulmonary edema, lactation failure, renal failure, hypovolaemic shock, hemolytic jaundice and DIC also noted. No maternal death was noted among study participants. Study observed $10 \%$ neonatal death and $18.0 \%$ still birth. Duhan et al observed $9.2 \%$ and Rathi et al noted $7.0 \%$ incidence of still birth. ${ }^{14,24}$

\section{Limitations}

Primary among these is the fact that the study is based on deliveries from a single hospital. This is a tertiary care referral hospital, and although the referral base did not change over the study period, we have no way of assessing whether more or different kinds of women at high risk for PPH were delivered at the study hospital over this period. Sample size was less. Need to conduct the study with large sample size to see the association of risk factor and PPH.

\section{CONCLUSION}

Present study observed that majority of the patients with PPH were in the age group of 20-34 years. The patients were mostly primiparous. The commonest associated medical condition was anemia. The commonest underlying cause of PPH was atonicity of the uterus. Commonest maternal outcome was fever. Out of total births, $72.0 \%$ were alive and healthy babies followed by $18.0 \%$ babies were still birth.
Health education is of utmost importance in poor and illiterate patients and those staying in remote places. All high-risk cases in remote places where the emergency services are not available should be referred to tertiary centre in time.

In high risk cases if etiological factors were identified and treated early the morbidity and mortality can be prevented.

Funding: No funding sources

Conflict of interest: None declared

Ethical approval: The study was approved by the Institutional Ethics Committee

\section{REFERENCES}

1. Lalonde A. International Federation of Gynecology and Obstetrics. Prevention and treatment of postpartum hemorrhage in low-resource settings. Int $\mathbf{J}$ Gynaecol Obstet. 2012;117:108-18.

2. Obstetrics Subgroup, Chinese Society of Obstetrics and Gynecology, Chinese Medical Association, Obstetrics Subgroup Chinese Society of Obstetrics, Gynecology Chinese Medical Association. Guideline of prevention and treatment about postpartum hemorrhage. Zhonghua $\mathrm{Fu}$ Chan Ke Za Zhi 2014;49:641-6.

3. Khan KS, Wojdyla D, Say L, Gulmezoglu AM, Look P. WHO analysis of causes of maternal death: a systematic review. Lancet. 2006;367:1066-74.

4. Carroli G, Cuesta C, Abalos E, Gulmezoglu AM. Epidemiology of postpartum haemorrhage: a systematic review. Best Pract Res Clin Obstet Gynaecol. 2008;22(6):999-1012.

5. Abouzahr C. Antepartum and postpartum haemorrhage. In: Murray CJ, Lopez AD, eds. Health Dimensions of Sex and Reproduction. Boston: Harvard University Press; 1998: 172-174.

6. Combs CA, Murphy EL, Laros RK Jr. Factors associated with postpartum hemorrhage with vaginal birth. Obstet Gynecol. 1991;77(1):69-76.

7. Magann EF, Evans S, Hutchinson M, Collins R, Howard BC, Morrison JC. Postpartum hemorrhage after vaginal birth: an analysis of the risk factors. South Med J. 2005;98:419-22.

8. Tsu VD. Postpartum haemorrhage in Zimbabwe: a risk factor analysis. $\mathrm{Br} \mathrm{J}$ Obstet Gynaecol. 1993;100(4):327-33.

9. Gilbert L, Porter W, Brown VA. Postpartum haemorrhage--a continuing problem. $\mathrm{Br} \mathrm{J}$ Obstet Gynaecol. 1987;94(1):67-71.

10. Sheiner E, Sarid L, Levy A, Seidman DS, Hallak M. Obstetric risk factors and outcome of pregnancies complicated with early postpartum haemorrhage: a population-based study. J Matern Fetal Neonatal Med. 2005;18:149-54.

11. Stones RW, Paterson CM, Saunders NJ. Risk factors for major obstetric haemorrhage. Eur J Obstet Gynecol Reprod Biol. 1993;48(1):15-8. 
12. Sosa CG, Althabe F, Belizan JM, Buekens P. Risk factors for postpartum hemorrhage in vaginal deliveries in a Latin-American population. Obstet Gynecol. 2009;113(6):1313-9.

13. Lalonde A, Daviss BA, Acosta A, Herschderfer K. Postpartum hemorrhage today: ICM/FIGO initiative 2004-2006. Int J Gynaecol Obstet. 2006;94(3):24353.

14. Duhan L Nanda S, Sirohiwal D, Dahiya P, Singhal S, Vandana. A retrospective study of maternal and perinatal outcome in patients of postpartum haemorrhage in a tertiary care hospital. Int J Reprod Contracept Obstet Gynecol. 2016;5:1897-901.

15. Kramer MS, Dahhou M, Vallerand D, Liston R, Joseph KS. Risk factors for postpartum hemorrhage: can we explain the recent temporal increase? J Obstet Gynaecol Can. 2011;33(8):810-9.

16. Sheldon WR, Blum J, Vogel JP, Souza JP, Gulmezoglu AM, Winikoff B; et al. Postpartum haemorrhage management, risks, and maternal outcomes: findings from the World Health Organization Multicountry Survey on Maternal and Newborn Health. BJOG. 2014;121:5-13.

17. Cotter AM, Ness A, Tolosa JE. Prophylactic oxytocin for the third stage of labor (review). Cochrane Database Syst Rev. 2001;201.

18. Jaleel R, Khan A. Post-partum haemorrhage--a risk factor analysis. Mymensingh Med J. 2010;19(2):2829.
19. Holm C, Langhoff RJ, Diness BR. Severe postpartum haemorrhage and mode of delivery: a retrospective cohort study. BJOG. 2012;119(5):596-604.

20. Wei Q, Xu Y, Zhang L. Towards a universal definition of postpartum hemorrhage: retrospective analysis of Chinese women after vaginal delivery or cesarean section. Medicine. 2020;99(33):21714.

21. Strand RT, Da Silva F, Jangsten E, Bergstrom S. Postpartum hemorrhage: a prospective, comparative study in Angola using a new disposable device for oxytocin administration. Acta Obstet Gynecol Scand. 2005;84(3):260-5.

22. Tourne G, Collet F, Lasnier P, Seffert P. Usefulness of collecting bag for the diagnosis of postpartum hemorrhage. J Gynecol Obstet Biol Reprod. 2004;33:229-34.

23. Bouwmeester FW, Bolte AC, Van Geijn HP. Pharmacological and surgical management for primary postpartum hemorrhage. Curr Pharma Des. 2005;11:759-73.

24. Rathi BA, Pawar SP. Clinical study of Maternal and perinatal outcome in antepartum haemorrhage at a tertiary care institute. MedPulse Int $\mathbf{J}$ Gynaecol. 2020;16(3):39-42.

Cite this article as: Shah AH, Panchal DN. A study of maternal and perinatal outcome in patients of postpartum hemorrhage in a tertiary care hospital, Gujarat. Int J Reprod Contracept Obstet Gynecol 2021;10:2286-90. 